\title{
Intravascular Release of Intact Cellular Fibronectin During Oxidant-induced Injury of the In Vitro Perfused Rabbit Lung
}

\author{
John H. Peters, Mark H. Ginsberg, Benjamin P. Bohl, Larry A. Sklar, and Charles G. Cochrane \\ Department of Immunology, Scripps Clinic and Research Foundation, La Jolla, California 92037; and Pulmonary Division, \\ Department of Medicine, University of California, San Diego, San Diego, California 92103
}

\begin{abstract}
Fibronectin (Fn) is produced by cells in blood vessels at inflammatory sites in vivo. Fn release into the circulation thus may be a marker for vascular injury. In support of this, we found that oxidant-induced vascular injury of isolated perfused rabbit lungs caused elevated circulating Fn levels. Western blot analysis indicated that Fn released from the injured blood vessels was intact, dimeric, and possessed electrophoretic mobility identical with Fn produced by fibroblasts. Unlike Fn isolated from rabbit plasma, Fn derived from lung perfusate or produced by fibroblasts reacted with antibodies raised to a synthetic peptide containing sequences from the extra type III Fn domain that is transcribed in fibroblasts but not hepatocytes. Vascular injury by protease was also associated with intravascular release of $F n$, but with cleavage. Oxidant-induced vascular injury causes release of tissue-derived Fn, which can be distinguished from plasma Fn by its size and content of antigenic determinants of the extra type III domain.
\end{abstract}

\section{Introduction}

Oxidants accumulate at sites of tissue inflammation involving neutrophils (1-4). The ability of antioxidants to block physiologic and morphologic disruption at these sites suggests that oxidants contribute to neutrophil-associated tissue injury (4-6). Oxidants probably cooperate with other inflammatory effector agents, however, including proteases, to cause tissue injury in vivo (2, $3,7,8$ ). In order to test the effects of antioxidants and antiproteases in experimental animals and humans, effector-specific biochemical markers of tissue injury are needed. Ideally, these markers should be soluble and present in blood and/or other accessible body fluids.

Fibronectins are large glycoproteins found in plasma, on cell surfaces, and in extracellular matrices. By binding other macromolecules as well as cells, they serve to promote anchorage of cells to substrata $(9,10)$. Fibronectins are composed of subunits of variable primary structure (average molecular weight $250 \mathrm{kD}$ ), which are disulfide-linked to form dimers or multimers (9-13). The predominant fibronectin in blood (plasma fibronectin) is

Address reprint requests to Dr. Peters, Department of Immunology, IMM12, Scripps Clinic and Research Foundation, 10666 North Torrey Pines Road, La Jolla, CA 92037. Clinic.

This is publication 4142IMM from the Research Institute of Scripps

Received for publication 24 December 1985 and in revised form 7 July 1986.

J. Clin. Invest.

(C) The American Society for Clinical Investigation, Inc.

$0021-9738 / 86 / 12 / 1596 / 08 \quad \$ 1.00$

Volume 78, December 1986, 1596-1603 secreted by hepatocytes, whereas cellular fibronectin is secreted by a variety of cultured cells including endothelial cells and fibroblasts (14-16). Despite extensive physical and immunologic similarities, the two classes of fibronectin differ in electrophoretic behavior, solubility, and biologic activities $(14,17,18)$. Primary structural differences between plasma and cellular fibronectins have been found by peptide mapping (19) and immunologic techniques (20). Recently, a difference region encoding for exactly one 90 -amino acid type III structural repeat was identified in messenger (m)RNA from human fibroblasts and two human tumor cell lines, but could not be detected in human liver mRNA $(13,21,22)$. Since plasma fibronectin is synthesized by hepatocytes, it is likely that the extra type III repeat is a unique domain of cellular fibronectins $(12,21,22)$.

Fibronectin accumulates at sites of injury and inflammation in vivo (23-27) and is produced by cells in blood vessel walls at these sites (28-31). We therefore asked if cellular fibronectin might accumulate in the vascular compartment and in other fluids in communication with sites of inflammatory tissue injury. We also asked if mediators of inflammatory tissue injury, including oxidants and proteases, could promote in situ release of cellular fibronectin. We chose to perform our studies in an in vitro perfused lung, since this model provides an abundantly vascular tissue that can be observed for both physiologic and biochemical changes under defined conditions.

\section{Methods}

Isolated perfused rabbit lung. Lungs from 2- to 2.5-kg New Zealand white rabbits were isolated and perfused as previously described (32) with the following modifications: a small animal ventilator (Harvard Instruments, Millis, MA) and a human coronary perfusion pump (Olson Medical Products, Ashland, MA) were used to provide ventilation and perfusion, respectively. $50 \mathrm{mg} / \mathrm{kg}$ ketamine (Parke-Davis Co., Morris Plains, NJ) and $10 \mathrm{mg} / \mathrm{kg}$ zylazine (Miles Laboratories, Shawnee, KA) were given intramuscularly as anesthesia for tracheotomy. After establishment of ventilation ( $15 \% \mathrm{O}_{2}, 5 \% \mathrm{CO}_{2}, 80 \% \mathrm{~N}_{2}$, respiratory rate 20 , tidal volume $10 \mathrm{ml} / \mathrm{kg}$, positive end-expiratory pressure $1 \mathrm{~cm} \mathrm{H}_{2} \mathrm{O}$ ), 32.5 $\mathrm{mg} / \mathrm{kg}$ sodium pentobarbital (Western Medical Supply, Arcadia, CA) was given prior to thoracotomy. All animals were anticoagulated with 1000 units of heparin (Elkins-Sinn, Cherry Hill, NJ) injected into the right ventricle 3 min prior to pulmonary artery cannulation. The perfusing buffer was a modified Krebs-Ringer bicarbonate buffer containing $2 \%$ bovine serum albumin (BSA) (Sigma Chemical Co., St. Louis, MO) warmed to $37.5^{\circ} \mathrm{C}$ with $\mathrm{pH}$ adjusted to between 7.3 and 7.4 after equilibration with the ventilating gas. After perfusion with $900 \mathrm{ml}$ of the perfusion buffer to wash away blood elements, each pair of lungs was suspended from a manual balance in a warmed humid chamber and perfused through the pulmonary artery at a rate of $125 \mathrm{ml} / \mathrm{min}$ with perfusate flowing by gravity from the left atrium into a $105-\mathrm{ml}$ recirculating reservoir. After $\sim 30 \mathrm{~min}$ of recirculation (15 min to prepare chamber and tubing and 15 min of equilibration), lung weight and pulmonary artery pressure (measured with a water manometer) were monitored and recorded every $10 \mathrm{~min}$ for $90 \mathrm{~min}$ of continuous perfusion 
and ventilation. Initial perfusate $\mathrm{pH}$ averaged 7.36 and did not differ significantly between experimental groups. $\mathrm{pH}$ at $90 \mathrm{~min}$ averaged 7.47 and also did not differ between groups.

\section{Injury models}

Oxidant injury. Lung vasculature was exposed to superoxide anion $\left(\mathrm{O}_{2}^{-}\right)$by introducing the substrate $7 \mathrm{H}$-imidazo(4,5-d)pyramidine (purine) (Sigma Chemical Co.) into the perfusion fluid reservoir at a concentration of $2 \mathrm{mM}$ at $15 \mathrm{~min}$, followed by xanthine oxidase (from bovine milk; Calbiochem-Behring Corp., La Jolla, CA) at a final concentration of $0.005 \mathrm{U} / \mathrm{ml}$ at $20 \mathrm{~min}$ into the experiment. Exposure of blood vessels to hydrogen peroxide $\left(\mathrm{H}_{2} \mathrm{O}_{2}\right)$ was achieved by constant infusion (Harvard infusion pump, Harvard Instruments) of $\mathrm{H}_{2} \mathrm{O}_{2}$ into the perfusate reservoir at a rate of $11 \mathrm{nmol} / \mathrm{ml}$ recirculating buffer $/ \mathrm{min}$ beginning at $20 \mathrm{~min}$ and continuing through the conclusion of the experiment at $90 \mathrm{~min}$. Catalase (from bovine liver; Sigma Chemical Co.) was added to the reservoir at $10 \mathrm{~min}$ (prior to oxidant) at a final concentration of $700 \mathrm{U} / \mathrm{ml}$ in those experiments where it was utilized to consume $\mathrm{H}_{2} \mathrm{O}_{2}$ in perfusion fluid. $\mathrm{H}_{2} \mathrm{O}_{2}$ and $\mathrm{O}_{2}^{-}$were measured fluorimetrically in $1-\mathrm{ml}$ aliquots of perfusion fluid taken at timepoints, using $240 \mu \mathrm{g}$ parahydroxyphenyl acetic acid, $40 \mu \mathrm{g}$ horseradish peroxidase (HRP), ${ }^{1}$ and $40 \mu \mathrm{g}$ superoxide dismutase (all from Sigma Chemical Co.) (33). The assay has a lower limit of detection of $\sim 1 \mu \mathrm{M} \mathrm{H}_{2} \mathrm{O}_{2}$ (equivalent to $2 \mu \mathrm{M} \mathrm{O}_{2}^{-}$) in perfusion fluid.

In lungs injured by $\mathrm{H}_{2} \mathrm{O}_{2}$ infusion, no $\mathrm{H}_{2} \mathrm{O}_{2}$ accumulation could be detected in the circulation throughout $90 \mathrm{~min}$ of perfusion despite significant signs of vascular dysfunction. When lungs were removed from the perfusion circuit, however, $\mathrm{H}_{2} \mathrm{O}_{2}$ concentration increased linearly with time and was stable for $30 \mathrm{~min}$ following completion of infusion. Similarly, neither $\mathrm{O}_{2}^{-}$nor its immediate dismutation product $\mathrm{H}_{2} \mathrm{O}_{2}$ could be detected in the perfusate at any timepoint during experiments in which xanthine oxidase and purine $(\mathrm{XO} / \mathrm{P})$ were added to generate $\mathrm{O}_{2}^{-}$ intravascularly. After removal from the lung circulation, however, aliquots of perfusion fluid generated $\mathrm{O}_{2}^{-}$at rates commensurate with enzyme and substrate concentration. These findings were unaffected by the presence or absence of perfusate cells in the sample being assayed.

Protease injury. Beginning at $20 \mathrm{~min}, N$-tosyl-L-phenylalanine chloromethyl ketone (TPCK)-treated trypsin (Sigma Chemical Co.) diluted in normal saline was constantly infused at $7.7 \mathrm{U} / \mathrm{ml}$ per min into the reservoir through the end of the $90-\mathrm{min}$ recirculation. To analyze delivery of protease to the lung vasculature, samples of perfusate were assayed for trypsin activity by following the change in absorbance over time at $405 \mathrm{~nm}$ when samples or standards were incubated with the substrate $N$-benzoyl-L-phenylalanyl-L-valyl-L-arginine-p-nitro-anilide hydrochloride (Kabi Diagnostica, Stockholm, Sweden). Lungs infused with trypsin showed linear increases in perfusate trypsin activity over time. The average concentration of trypsin in perfusate changed linearly from $7 \pm 4 \mathrm{U} / \mathrm{ml}$ at $30 \mathrm{~min}$ ( $10 \mathrm{~min}$ after onset of infusion) to $356 \pm 35 \mathrm{U} / \mathrm{ml}$ at $90 \mathrm{~min}$.

The doses of oxidants and trypsin used had been determined in preliminary experiments to produce significant increases in lung weight and lavage protein concentration compared with controls within a 90-min recirculation, consistent with vascular dysfunction.

Preparation of fluid samples. 2.5-ml samples of perfusion fluid were taken from the reservoir at $0,30,60$, and $90 \mathrm{~min}$. At the completion of each 90-min experiment, a narrow bore tube was quickly inserted into the right mainstem bronchus and the lower lobe was lavaged with $5 \mathrm{ml}$ of ice-cold modified Gey's buffer-carbonate. The average volume recovered was $2.8 \mathrm{ml}$ and did not differ significantly between experimental groups. Samples of perfusate and bronchoalveolar lavage (BAL) were

1. Abbreviations used in this paper: BAL, bronchoalveolar lavage; ED, extra type III domain; ELISA, enzyme-linked immunosorbent assay; $\mathrm{GO} / \mathrm{G}$, glucose oxidase-glucose; HRP, horseradish peroxidase; PAP, pulmonary artery pressure; $P M S F$, phenylmethylsulfonyl fluoride; SDSPAGE, sodium dodecyl sulfate polyacrylamide gel electrophoresis; TBS, Tris-buffered saline; TLCK, $N$ (alpha)-p-tosyl-L-lysine chloromethyl ketone; TPCK, $N$-tosyl-L-phenylalanine chloromethyl ketone; $\mathrm{XO} / \mathrm{P}$, xanthine oxidase-purine. immediately centrifuged at $11,600 \mathrm{rpm}$ for $8 \mathrm{~s}$. Cell pellets were resuspended in $2 \%$ acetic acid for counts and differentials by hemocytometer. Supernatants were snap-frozen and stored at $-70^{\circ} \mathrm{C}$ pending assay for fibronectin by enzyme-linked immunoassay (ELISA). Prior to freezing, fluids from trypsin-injured lungs to be assayed by ELISA were immediately (within $30 \mathrm{~s}$ ) made $0.2 \mathrm{mM}$ with lima bean trypsin inhibitor (LBTI) (Worthington Biochemical Co., Freehold, NJ) (100-fold molar excess over maximum trypsin concentrations reached in perfusate) and $6 \mathrm{mM} N$ (alpha)-p-tosyl-L-lysine chloromethyl ketone (TLCK) (Sigma Chemical Co.) (3,000-fold molar excess). 90-min perfusate samples so treated had activity in the trypsin assay approximating background activity in samples from control lungs at the same time point $(2.4 \pm 0.6 \mathrm{U} /$ $\mathrm{ml}$ in inhibited samples compared with $2.0 \pm 0.2 \mathrm{U} / \mathrm{ml}$ in control samples).

Perfusate and BAL supernatants were prepared for polyacrylamide gel electrophoresis in the presence of sodium dodecyl sulfate (SDS-PAGE) by boiling for $4 \mathrm{~min}$ with an equal volume of 10\% SDS in Laemmli sample buffer $(0.5 \mathrm{M}$ Tris $\mathrm{pH} 6.8)$ preheated to $100^{\circ} \mathrm{C}$ with or without $3 \%$ beta mercaptoethanol (34). Preliminary experiments had shown that immediate boiling in SDS halted progressive proteolysis of fibronectin in tissue fluids to which proteases had been added. Therefore, fluids from lungs injured with trypsin were boiled in SDS immediately (within 30 s) after removal from the lung circulation. Fluids from control and oxidant-injured lungs, however, could be boiled in SDS at a later time after freezing without effect on the integrity of fibronectin.

Preparation of lung tissue samples. At the conclusion of each experiment small sections were cut from the middle of one lower lobe and placed in 10\% neutral-buffered formalin for light microscopy. Additionally, a piece of lung parenchyma from a lower lobe was immediately clamped with tongs precooled in liquid nitrogen. The frozen lung was homogenized for $30 \mathrm{~s}$ in a liquid nitrogen-cooled 3-ml Teflon cartridge using a Mikro-dismembrator (B. Braun Instruments, Melsungen, Federal Republic of Germany), yielding $\sim 50 \mathrm{mg}$ of frozen powder. $500 \mu \mathrm{l}$ of boiling sample buffer were then added to the frozen lung powder derived from homogenization, and the resulting suspension was vortexed and boiled for an additional $4 \mathrm{~min}$. Insoluble lung material was then pelleted by centrifugation, and samples of the supernatant subjected to SDSPAGE.

Examination of fibronectins by Western transfer. Electrophoresis was performed in low percentage or gradient SDS-polyacrylamide gels. The proteins in the gels were electrophoretically transferred to nitrocellulose sheets (Millipore Corp., Bedford, MA) (35). After transfer, the sheets were blocked with $3 \%$ gelatin in Tris-buffered saline pH 7.4 (TBS) for 30 minutes and then soaked overnight in 1\% gelatin in TBS containing goat antifibronectin antibodies. After washing in TBS containing $0.05 \%$ Tween 20, the sheets were soaked for $90 \mathrm{~min}$ in $1 \%$ gelatin in TBS containing HRP-conjugated swine antibodies to goat IgG. The sheets were washed prior to visualization of immunoreactive protein bands by incubation with $0.05 \% \mathrm{H}_{2} \mathrm{O}_{2}$ and $0.5 \mathrm{mg} / \mathrm{ml} \mathrm{HRP} \mathrm{Color} \mathrm{Development}$ Reagent (Bio-Rad Laboratories, Richmond, CA) in TBS containing 17\% methanol for $30 \mathrm{~min}$. Because the BSA in the perfusion buffer contained traces of bovine IgG with which the swine antibodies reacted, these antibodies were absorbed with bovine IgG (Calbiochem-Behring Corp.) immobilized on Sepharose beads prior to use in staining Western transfers in which samples of whole perfusate (rather than isolated fibronectins) were examined.

Isolation of fibronectins. Fibronectin was purified from rabbit plasma, pooled lung perfusate, human plasma, fetal bovine serum, and conditioned media (Dulbecco's modified Eagle's medium containing 10\% fibronectin-depleted fetal bovine serum) from confluent GM-1380 human fibroblasts and RAB-9 rabbit fibroblasts by affinity chromatography on gelatin Sepharose (36).

To compare electrophoretic mobility of Fns contained in small samples of lung perfusate, lavage, and tissue, distortions in electrophoretic mobility due to other proteins was minimized by isolating fibronectin using small nonlimiting quantities of gelatin agarose beads (Pierce Chemical Co., Rockford, IL) (14). $100 \mu$ l of perfusate or lavage were shaken with $40 \mu \mathrm{l}$ of packed gelatin beads for $15 \mathrm{~min}$ at room temperature, pelleted by centrifugation, and washed three times with PBS containing 
2 mM EDTA prior to elution with $100 \mu l$ of sample buffer. Lung tissue fibronectin was isolated by first shaking $\sim 20 \mathrm{mg}$ of lyophilized powder (2) from perfused (bloodless) rabbit lung tissue with $1 \mathrm{ml}$ of 2 molar urea, $10 \mathrm{mg} / \mathrm{ml}$ porcine intestinal heparin (Sigma Chemical Co.), and 2 $\mathrm{mM}$ phenylmethylsulfonyl fluoride (PMSF) in PBS at room temperature for $4 \mathrm{~h}$ (37). The supernatant from the resulting suspension was diluted 10-fold with PBS and shaken with gelatin agarose beads prior to washing and elution with sample buffer.

Synthesis of human fibronectin extra domain peptide. The 90 amino acid extra type III domain of human fibronectin contains a region occurring 36 to 60 amino acids from its amino terminal end in which there is a relative absence of sequence homology with other type III repeats (13). The 19 amino acid peptide ELFPAPDGEEDTAELQGGC was therefore synthesized using solid phase methodology on peptide synthesizer (model 438, Applied Biosystems, Foster City, CA) (38). The Nterminal 17 amino acids of the peptide represent a region of the extra domain running 45 to 61 amino acids from its amino terminus. The carboxy terminal glycine and cysteine were added for linkage to the solid phase. The peptide migrated $>90 \%$ in a single peak when subjected to high performance liquid chromatography using a C18 column (Vydac, Western Analytical Products, Temecula, CA). To confirm amino acid composition, the peptide was hydrolyzed in $6 \mathrm{~N}$ hydrochloric acid for $24 \mathrm{~h}$ at $110^{\circ} \mathrm{C}$, dried overnight, and then applied to an amino acid analyzer column (Beckman 121-M, Beckman Instruments, Inc., Fullerton, CA). The individual amino acid contents conformed $99.9 \%$ with the desired peptide composition.

Antifibronectin antibodies. Antibodies to rabbit plasma fibronectin were raised in a goat by weekly multiple intradermal injections of 100 $\mu \mathrm{g}$ of purified antigen emulsified in Freund's adjuvant (Difco Laboratories, Detroit, MI). Antibodies to the extra type III domain of human fibronectin were similarly raised in goats by weekly intradermal injections in adjuvant of $150 \mu \mathrm{g}$ of the extra domain peptide (ED peptide) coupled to keyhole limpet hemocyanin (Pacific Bio-Marine, Venice, CA) by the glutaraldehyde method (39). Antibody titers specific for the ED peptide were checked by ELISA (40).

To insure that the anti-ED peptide antibodies were in fact reactive with nonhepatic (cellular) but not hepatic (plasma) fibronectin, equal quantities of fibronectin purified from human plasma and GM-1380 cultured human fibroblast media (containing fibronectin-depleted fetal bovine serum) were subjected to SDS-PAGE with Western transfer. Protein concentrations were determined with BCA protein assay reagent (Pierce Chemical Co., Rockford, IL) using BSA as a standard. Staining was achieved with goat anti-ED peptide antibodies, goat anti-ED peptide antibodies preincubated with ED peptide, or goat anti-rabbit plasma fibronectin antibodies (crossreactive with human fibronectin). As seen in Fig. 1, the anti-ED peptide antibodies did not react with fibronectin isolated from human plasma, but did react specifically with fibronectin isolated from human fibroblast conditioned media.

Measurement of fibronectin in fluid samples. A quantitative noncompetitive ELISA was constructed using rabbit plasma fibronectin standards (41). Wells of microtiter plates were first coated with goat antirabbit plasma fibronectin antibodies immunopurified as described (11) and diluted in $0.1 \mathrm{M} \mathrm{NaHCO}_{3}$. Next, standards and samples, both diluted in perfusion buffer ( $2 \% \mathrm{BSA}$ ) were applied. Finally, immunopurified goat antirabbit plasma fibronectin antibodies conjugated to alkaline phosphatase (from bovine intestinal mucosa; Sigma Chemical Co.) with glutaraldehyde (41) were applied. $p$-Nitrophenyl phosphate (Sigma Chemical Co.) at $1 \mathrm{mg} / \mathrm{ml}$ in $1 \mathrm{M}$ diethanolamine $\mathrm{pH} 9.8$ was utilized as substrate for color development. A sigmoid standard curve was established by the relationship between the log of the concentration of rabbit plasma fibronectin standards or sample dilutions and the absorbance reading at $405 \mathrm{nM}$ after 120 min of color development.

Measurement and characterization of total BAL protein. Total protein in BAL samples was measured by the method of Lowry et al. (42), using BSA as a standard. Additionally, $2 \mu \mathrm{l}$ of BAL fluid from each experiment were subjected to SDS-PAGE using a 5-20\% SDS-acrylamide gradient under both reducing and nonreducing conditions. Visualization of resulting protein bands was achieved by Coomassie Brilliant Blue staining.

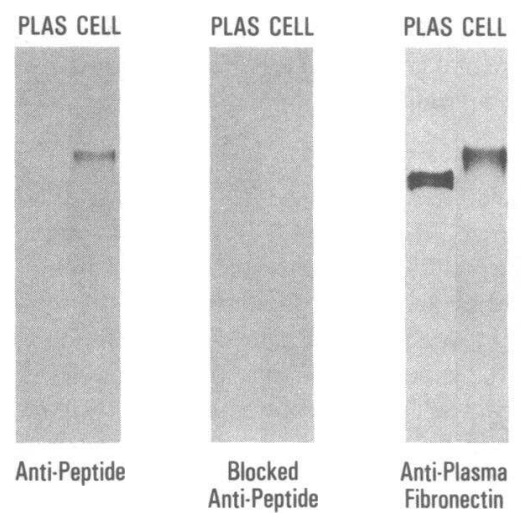

Figure 1. Antibodies to the extra domain peptide react specifically with human cellular fibronectin. Equal amounts $(0.5 \mu \mathrm{g})$ of fibronectin purified by gelatin affinity chromatography from human plasma and GM-1380 human fibroblast media (containing fibronectin-depleted fetal calf serum) were subjected to SDS-PAGE (reducing conditions) and Western transfer in paired lanes. Staining was accomplished with (from left to right) anti-ED peptide serum, anti-ED peptide serum preincubated with $100 \mu \mathrm{g} / \mathrm{ml}$ ED peptide, and anti-plasma fibronectin antibodies.

Data presentation and statistics. Values were expressed as mean \pm SEM. Statistical analyses were performed by use of the Student's two-tailed $t$ test. $P$ values $<0.05$ were significant.

\section{Results}

Effect of oxidant or protease treatment on fibronectin concentrations in perfusion fluid and alveolar lavage. Fibronectin was not detected in the BSA-containing perfusion buffer by either ELISA or Western transfer prior to circulation through rabbit lungs. However, low levels $(0.3$ to $1.0 \mu \mathrm{g} / \mathrm{ml})$ of rabbit fibronectin accumulated in the recirculating perfusate during the $30-\mathrm{min}$ equilibration period prior to experimental observation. Over the course of the ensuing 90 min, perfusion fluid of oxidant-injured lungs accumulated significantly greater levels of fibronectin than uninjured controls or catalase-protected lungs (Table I). Accelerated rates of accumulation of fibronectin in perfusion fluid of oxidant-injured lungs began in the period between 30 and 60 minutes (between 10 and 40 min after addition of oxidant to perfusion fluid). Edema formation, measured as increase in lung weight, generally began to occur at $\sim 30 \mathrm{~min}$. Fig. 2 plots both perfusion fluid fibronectin concentration (measured every 30 $\mathrm{min}$ ) and lung weight gain (measured every $10 \mathrm{~min}$ ) as a function of time.

In contrast to the oxidant injury model, continuous trypsin infusion caused edema formation between 60 and $90 \mathrm{~min} \mathrm{(40-}$ $70 \mathrm{~min}$ after onset of infusion). Perfusate fibronectin levels measured by ELISA decreased throughout the trypsin infusion, including the period of edema formation (Fig. 2).

Fibronectin retrieved by lavage of the alveolar space at 90 min was elevated in oxidant-treated groups compared with controls. Catalase pretreatment of perfusion fluid prior to addition of oxidants prevented the increase in BAL fibronectin associated with oxidant exposure (Table I).

Physical characteristics of fibronectin in perfusate, lavage, and lung tissue after oxidant or protease treatment. Fibronectin in perfusate of lungs treated with oxidants was intact and dimeric ( $510 \mathrm{kD}$ ) (Fig. $3 A$ ). Under reducing conditions the subunits of perfusate fibronectin showed similar electrophoretic mobility to 
Table I. Fibronectin Levels in Perfusate and Lavage Fluid of Isolated Perfused Lungs*

\begin{tabular}{lll}
\hline Group & Perfusate & Lavage \\
\hline $\begin{array}{c}\mu g / m l \\
\text { Controls } \\
n=9\end{array}$ & $1.5 \pm 0.3$ & $0.04 \pm 0.01$ \\
$\mathrm{H}_{2} \mathrm{O}_{2}$ & & \\
$n=6$ & $10.5 \pm 1.9 \ddagger$ & $0.41 \pm 0.12 \ddagger$ \\
$\mathrm{H}_{2} \mathrm{O}_{2}+$ catalase & $1.4 \pm 0.3$ & $0.06 \pm 0.02$ \\
$n=4$ & & \\
$\mathrm{XO} / \mathrm{P}$ & $10.9 \pm 1.7 \ddagger$ & $0.28 \pm 0.13 \ddagger$ \\
$n=4$ & & \\
$\mathrm{XO} / \mathrm{P}+$ catalase & $1.6 \pm 0.2$ & $0.07 \pm 0.02$ \\
$n=4$ & & \\
Trypsin & & \\
$n=6$ & $0.1 \pm 0.0 \ddagger$ & $0.07 \pm 0.01$ \\
& & \\
\hline
\end{tabular}

* Samples for assay were taken after 90 min of experimental observation. Fibronectin was measured by ELISA, using rabbit plasma fibronectin standards.

$\ddagger P<0.05$ compared with control group.

subunits of fibronectin extracted from normal rabbit lung tissue (Fig. $3 \mathrm{~B})$. Both migrated as single bands $(\sim 260 \mathrm{kD})$ in conventional low percentage gels. These bands were of a higher apparent molecular weight than either of the bands formed by the subunits of rabbit plasma fibronectin (210 and $240 \mathrm{kD}$ ). Rabbit plasma fibronectin diluted in perfusion buffer and subjected to $2 \mathrm{mM} \mathrm{H}_{2} \mathrm{O}_{2}$ for $90 \mathrm{~min}$ showed no change in electrophoretic behavior (not shown). In order to resolve small differences in electrophoretic mobility between subunits, samples of fibronectin were also subjected to prolonged electrophoresis under reducing conditions. Duration of electrophoresis was calibrated by the position of prestained molecular weight standards (Bethesda Research Laboratories, Bethesda, MD). Under these conditions, the subunits of perfusate fibronectin resolved into a doublet possessing electrophoretic mobility identical with that of fibronectin isolated from the media of rabbit fibroblasts which had been grown in fibronectin-depleted media (see Methods) (Fig. $3 C$ ). Treatment of the lung vasculature with either $\mathrm{O}_{2}^{-}$or $\mathrm{H}_{2} \mathrm{O}_{2}$ caused intravascular release of fibronectin of similar subunit composition.

Fibronectin in the perfusion fluid of all trypsin-treated lungs was progressively cleaved over time. As shown in Fig. 4, the fibronectin that accumulated in the 30 -min period of recirculation prior to time $=0 \mathrm{~min}$, was intact and of higher molecular weight than plasma fibronectin. At later time points, it was replaced with cleavage products concomitant with administration of trypsin. Lavage fluid from protease-injured lungs also contained fibronectin fragments, and these comigrated with fragments in perfusion fluid and lung tissue extracts taken at the corresponding timepoint. In contrast, intact fibronectin was detected in BAL and lung tissue extracts from oxidant-injured lungs (not shown).

The fibronectin that accumulated at low levels in control and catalase-protected lungs was physically indistinguishable from oxidant-released fibronectin when examined with Western transfer using increased quantities of isolated antigen and/or antifibronectin antibody concentrations (not shown).

Effect of proteolysis of fibronectin on measurement by ELISA. Serial threefold dilutions ( 10 to $0.014 \mu \mathrm{g} / \mathrm{ml}$ ) of purified rabbit plasma fibronectin in either perfusion buffer, perfusion buffer containing LBTI and TLCK, or perfusion buffer containing trypsin alone were kept at $4^{\circ} \mathrm{C}$ for $2 \mathrm{~h}$. After incubation, samples containing trypsin alone were then also treated with LBTI and TLCK. The final concentrations of trypsin, LBTI, and TLCK were equal to those achieved in inhibited perfusate (see Preparation of Fluid Samples) samples from trypsin-treated lungs at $90 \mathrm{~min}$. ELISA-derived fibronectin concentrations in samples incubated with trypsin and inhibitors averaged $97 \%$, whereas concentrations in samples containing uninhibited trypsin averaged $43 \%$ of values for dilutions of fibronectin in perfusate alone. Western transfer examination of the samples confirmed that fibronectin exposed to trypsin without inhibitors was proteolytically degraded. In contrast, fibronectin in samples containing no trypsin or inhibited trypsin remained intact (not shown).

Electrophoretic examination of perfusion fluid fibronectin using anti-extra domain antibodies. Although fibronectin in the circulation of oxidant-treated lungs possessed electrophoretic mobility consistent with cellular fibronectin, we sought to confirm this designation by testing its reactivity with anti-ED antibodies. Antibodies to the human ED peptide stained fibronectin from perfusion fluid of oxidant-injured rabbit lungs but not equal quantities of fibronectin isolated from rabbit plasma. Staining was prevented when anti-peptide serum was preincubated with ED peptide. Only the upper band of the perfusate fibronectin doublet (detected with anti-plasma fibronectin antibodies) was stained by antiserum to the ED peptide. In contrast, dimeric perfusate fibronectin of uniform mobility was detected by both

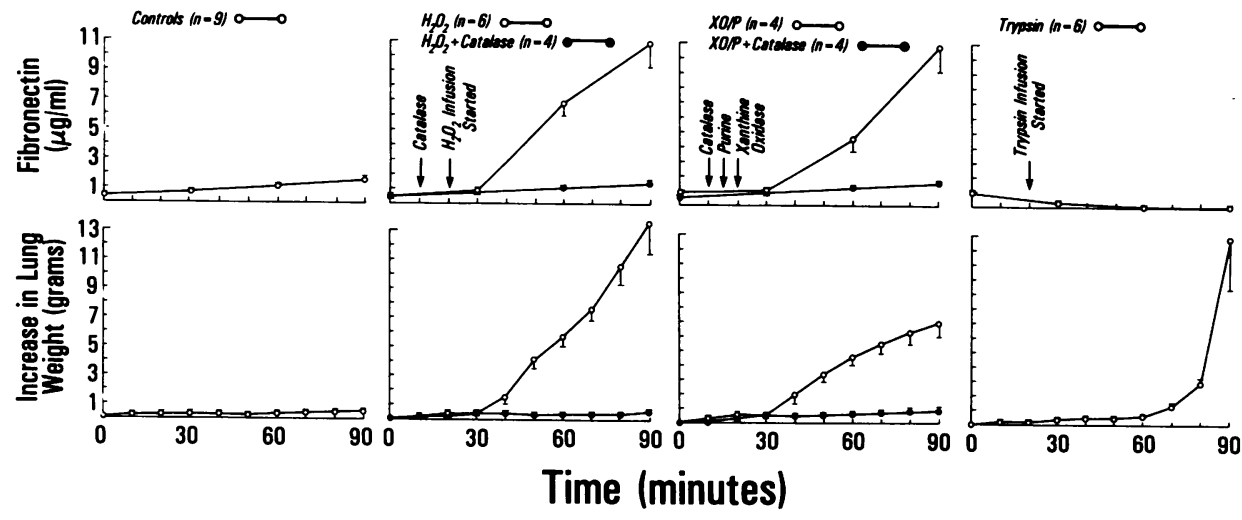

Figure 2. Temporal relationship between perfusate fibronectin concentration measured by ELISA and increase in lung weight for (starting from left) uninjured control lungs, lungs exposed to $\mathrm{H}_{2} \mathrm{O}_{2}$ with or without catalase protection, lungs exposed to $\mathrm{O}_{2}^{-}$with or without catalase protection, and lungs exposed to trypsin. 
A

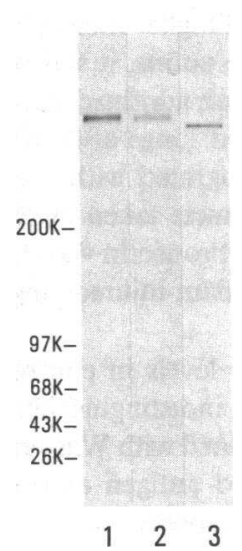

B

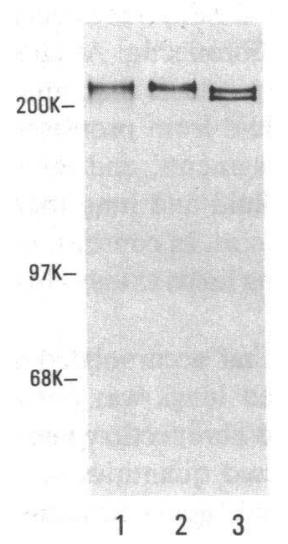

C

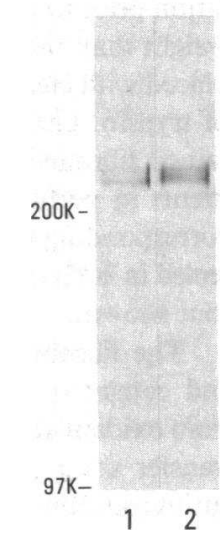

Figure 3. Comparison of fibronectins. Rabbit fibronectins from different sources were subjected to SDS-PAGE and Western transfer and stained using antirabbit plasma fibronectin antibodies. Samples in $(A)$ were nonreduced; samples in $(B)$ and $(C)$ were reduced. $(A)$ Equal volumes $(10 \mu \mathrm{l})$ of perfusion fluid obtained at $90 \mathrm{~min}$ from representative lungs injured with $\mathrm{H}_{2} \mathrm{O}_{2}$ (lane 1 ) or $\mathrm{O}_{2}^{-}$(lane 2), and rabbit plasma fibronectin diluted in perfusion buffer (final fibronectin concentration of $10 \mu \mathrm{g} / \mathrm{ml}$ ) (lane 3) were subjected to 3-20\% gradient SDS-PAGE without prior isolation of fibronectin. In addition to the predominant dimeric form of fibronectin (shown here), very faint staining of material with mobility consistent with multimeric and/or monomeric fibronectin was occasionally observed when nonreduced perfusate was subjected to Western blotting. (B) Similar quantities of fibronectin were isolated on gelatin agarose beads from $(I)$ a heparin urea extract (see Methods) of uninjured perfused (bloodless) lung tissue, (2) perfusion fluid obtained at 90 min from a lung injured by $\mathrm{H}_{2} \mathrm{O}_{2}$ infusion, and (3) rabbit plasma. Lung tissue fibronectin was prepared by absorbing 1 $\mathrm{ml}$ of diluted heparin urea extract (see Methods) with $40 \mu \mathrm{l}$ of gelatin beads, eluting with $100 \mu \mathrm{l}$ of sample buffer, and subjecting $20 \mu \mathrm{l}$ of eluate to electrophoresis. Fibronectin was similarly isolated from perfusion fluid except that $100 \mu \mathrm{l}$ were absorbed and $20 \mu \mathrm{l}$ of eluate were subjected to electrophoresis. Approximately $400 \mathrm{ng}$ of rabbit plasma fibronectin was run in lane 3. (C) Similar quantities of gelatin-isolated fibronectins obtained from rabbit fibroblast media (containing fibronectin-depleted fetal bovine serum) (lane 1 ) and from perfusion fluid from an $\mathrm{H}_{2} \mathrm{O}_{2}$-injured lung (lane 2) were subjected to prolonged electrophoresis in a $5 \%$ gel.

types of antibody under nonreducing conditions (Fig. 5). Antibodies to the ED peptide also specifically stained higher molecular weight subunits of the intact fibronectin that accumulated at low levels in perfusion fluid of uninjured lungs (not shown).

Electrophoretic examination of rabbit fibroblast fibronectin using anti-extra domain antibodies. Cellular fibronectin isolated from rabbit fibroblast media was heterodimeric with two major subunit populations that comigrated with those of rabbit lung perfusate fibronectin. Like perfusate fibronectin, only the slower migrating subunit population stained with anti-ED antibodies (Fig. 6).

Effects of oxidant or protease treatment on parameters of lung vascular function. All lungs subjected to the cited doses of injurious agents were observed for $90 \mathrm{~min}$ of recirculation and ventilation. Net increase in lung weight over this period and BAL protein concentration were significantly increased in lungs treated with oxidants or protease compared with controls (Table II). Increase in pulmonary artery pressure (PAP) over baseline was also greater in the oxidant and protease-treated groups than

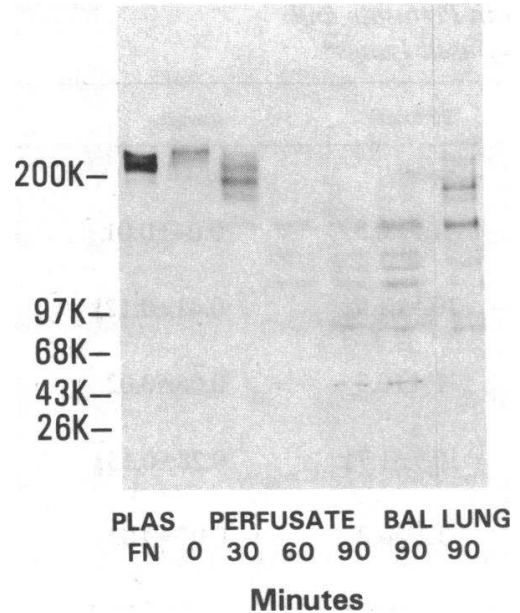

Figure 4. Fibronectin samples in perfusate, lavage from a representative trypsin-injured rabbit lung. From left to right: plasma fibronectin $(50 \mathrm{ng})$, serial perfusate samples $(10 \mu \mathrm{l})$, BAL $(20 \mu \mathrm{l})$, and SDS-extract of lung tissue $(5 \mu \mathrm{l}$ of supernatant from a $100-\mathrm{mg} / \mathrm{ml}$ suspension of lung tissue homogenate in sample buffer). Fluid samples were boiled in SDS immediately after removal from the lung, or in the case of lung tissue, after homogenization in a liquid nitrogen-cooled cartridge

PAGE and Western transfer with staining by anti-rabbit plasma fibronectin antibodies.

controls, but only significantly so in the $\mathrm{H}_{2} \mathrm{O}_{2}$-injury group. Pretreatment of perfusion fluid with catalase prevented disruption of all three parameters of vascular function by either $\mathrm{H}_{2} \mathrm{O}_{2}$ or $\mathrm{O}_{2}^{-}$. The group treated with catalase prior to $\mathrm{XO} / \mathrm{P}$ showed a small decrease in PAP compared with baseline.

SDS-PAGE of BAL fluids with elevated protein concentra- a

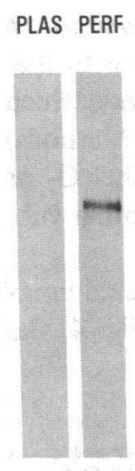

12

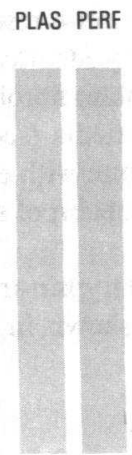

34

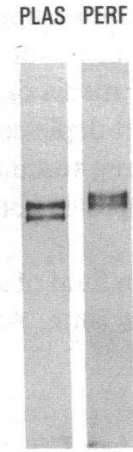

56 b

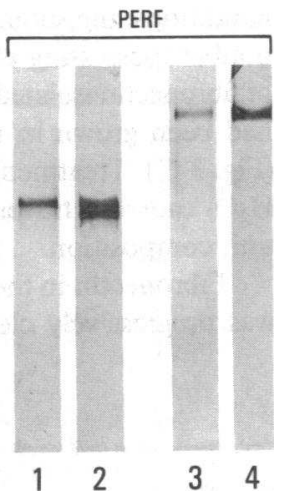

Figure 5. Antibodies to extra domain peptide react specifically with perfusate fibronectin. Equal amounts of fibronectin isolated from rabbit plasma or perfusion fluid obtained from $\mathrm{H}_{2} \mathrm{O}_{2}$-injured lungs at 90 min were subjected to prolonged 5\% SDS-PAGE and Western transfer in parallel. (a) After electrophoresis under reducing conditions, electrophoretically transferred fibronectins were stained with antipeptide serum (lanes 1 and 2), antipeptide serum preincubated with peptide at $750 \mu \mathrm{g} / \mathrm{ml}$ (lanes 3 and 4), or antirabbit plasma fibronectin antibodies (lanes 5 and 6). (b) Perfusate fibronectin under reducing (lanes 1 and 2) and nonreducing (lanes 3 and 4 ) conditions. Staining was achieved with antipeptide serum (lanes 1 and 3 ) or antiplasma fibronectin antibodies (lanes 2 and 4 ). 


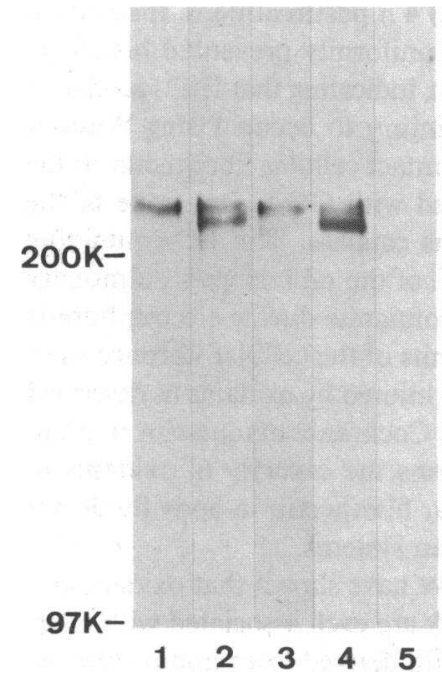

tal bovine serum) of confluent rabbit fibroblasts was accomplishe mixing $100 \mu \mathrm{l}$ of packed gelatin agarose beads with $4 \mathrm{ml}$ of media followed by elution with $100 \mu \mathrm{l}$ of sample buffer. To examine the possibility that fibronectin detected in fibroblast media might represent a mixture of rabbit cellular fibronectin and residual bovine fibronectin, $4 \mathrm{ml}$ of media not previously exposed to fibroblasts was subjected to affinity-isolation as described above. In lane $5.30 \mu$ lof the resulting eluate was subjected to electrophoresis and Western transfer with staining by antiplasma fibronectin antibodies (identical conditions as lanes 2 and 4 ).

tion uniformly revealed that the predominant protein band comigrated with the BSA in the perfusion fluid (not shown).

Cellular composition of perfusate and lung tissue. In all experiments, the majority of nonerythrocytic cells identified by hemocytometer in perfusion fluid samples were mononuclear with large round nuclei. Wright-stained smears of these cells revealed that they possessed granular cytoplasm and were similar in size to polymorphonuclear leukocytes also detected in per-

Table II. Evidence of Vascular Dysfunction*

\begin{tabular}{llll}
\hline Group & $\begin{array}{l}\text { Change in } \\
\text { lung weight }\end{array}$ & $\begin{array}{l}\text { Change in } \\
\text { PAP }\end{array}$ & $\begin{array}{l}\text { BAL protein } \\
\text { concentration }\end{array}$ \\
\hline $\begin{array}{l}\text { Controls } \\
n=9\end{array}$ & $g$ & $c m H_{2} \mathrm{O}$ & $\mathrm{mg} / \mathrm{ml}$ \\
$\begin{array}{c}\mathrm{H}_{2} \mathrm{O}_{2} \\
n=6\end{array}$ & $0.5 \pm 0.2$ & $1.2 \pm 0.3$ & $0.4 \pm 0.1$ \\
$\begin{array}{c}\mathrm{H}_{2} \mathrm{O}_{2}+\text { catalase } \\
n=4\end{array}$ & $0.5 \pm 0.1$ & $0.01 \pm 0.5$ & $0.7 \pm 0.1$ \\
$\begin{array}{c}\mathrm{XO} / \mathrm{P} \\
n=4\end{array}$ & $6.9 \pm 0.9 \S$ & $2.4 \pm 0.5$ & $1.1 \pm 0.3 \S$ \\
$\begin{array}{c}\mathrm{XO} / \mathrm{P}+\text { catalase } \\
n=4\end{array}$ & $0.85 \pm 0.3$ & $-0.6 \pm 0.9 \S$ & $0.4 \pm 0.1$ \\
$\begin{array}{c}\mathrm{T} \text { Trypsin } \\
n=6\end{array}$ & $12.9 \pm 3.5 \S$ & $3.1 \pm 0.9$ & $5.4 \pm 2.0 \S$ \\
\hline
\end{tabular}

* Changes in lung weight and PAP represent differencès between measurements at 0 and $90 \mathrm{~min}$ of experimental observation. Values are positive unless otherwise indicated.

$¥$ BAL was obtained after 90 min of experimental observation. $\S P<0.05$ compared with the control group. fusate. Although total cell number in perfusion fluid was noted to increase over time in all experiments, significant differences in counts did not occur between experimental groups at time points. At time $=90 \mathrm{~min}$, circulating mononuclear and polymorphonuclear cell counts were $76.7 \pm 10.4$ and $4.3 \pm 0.5 \times 10^{3}$ cells $/ \mathrm{ml}$ in nine lungs of control animals, $66.3 \pm 12.9$ and $4.3 \pm 0.6$ $\times 10^{3}$ cells/ml in six $\mathrm{H}_{2} \mathrm{O}_{2}$-treated lungs, $88.0 \pm 19.9$ and $3.7 \pm 0.7$ $\times 10^{3}$ cells $/ \mathrm{ml}$ in four catalase-protected $\mathrm{H}_{2} \mathrm{O}_{2}$-treated lungs, $82.4 \pm 14.1$ and $2.2 \pm 0.8 \times 10^{3} \mathrm{cells} / \mathrm{ml}$ in four XO/P-treated lungs, $70.7 \pm 23.5$ and $2.4 \pm 0.8 \mathrm{cells} / \mathrm{ml}$ in four catalase-protected $\mathrm{XO} / \mathrm{P}$-treated lungs, and $84.9 \pm 8.0$ and $1.9 \pm 0.7 \times 10^{3}$ cells $/ \mathrm{ml}$ in six trypsin-treated lungs.

No significant differences in morphology or cellularity could be detected between oxidant-injured and uninjured lungs by light microscopy. In contrast, frequent thinning, elongation, and rupture of alveolar septae were noted in protease injured lungs (not shown).

\section{Discussion}

The data presented in this study show that oxidant and proteaseinduced vascular injury are each associated with characteristic effector-specific changes in pulmonary tissue fibronectin in vitro.

Intact fibronectin dimers are released into blood vessels of isolated perfused rabbit lungs in response to levels of circulating oxidants that lie within the consumptive capabilities of lung antioxidant defenses. These levels of oxidants nevertheless cause vascular dysfunction (evident as lung weight gain), and this process correlates temporally with fibronectin release. When subjected to electrophoresis, subunits of the released fibronectin migrate more slowly than those of rabbit plasma fibronectin. This is typical of human, chicken, rat, and hamster cellular fibronectins in comparison with their plasma counterparts (14, 17, 43). Additionally, the released fibronectin shows similar electrophoretic mobility to fibronectin extracted from normal rabbit lung tissue perfused free of blood elements. Finally, the perfusion fluid fibronectin possesses electrophoretic mobility which is identical with rabbit fibroblast-derived cellular fibronectin. Therefore, the fibronectin released by the oxidant-injured vasculature of the in vitro perfused lung appears by electrophoretic comparisons to be cellular fibronectin.

To confirm the designation of perfusate fibronectin as cellular fibronectin we exploited the known differences in primary structure between non-hepatic (cellular) and hepatic (plasma) fibronectins (13). The feasibility of this approach was recently demonstrated by Hynes (personal communication) who showed that antibodies to a fusion protein containing an extra type III repeat of rat fibronectin reacted with subunits of rat cellular but not rat plasma fibronectin. In agreement with Hynes' findings, we were able to prepare antibodies to an amino acid sequence within the extra type III domain of human fibronectin that reacted exclusively with human and rabbit cellular, but not plasma fibronectins. The reactivity of these antibodies with rabbit lung perfusate fibronectin identifies this protein as cellular fibronectin.

Because fluid accumulation by the oxidant-injured lungs (measured as weight gain) accounted for less than a $20 \%$ additional contraction of the recirculating volume, the greater than sixfold average increase in fibronectin concentration achieved in the circulation of these lungs compared with uninjured lungs must be attributed to intravascular release rather than concentration. The mechanism of vascular release of intact cellular fibronectin in response to oxidants remains unclear. Fibronectin 
could be dislodged from extracellular sites or released by cells in proximity to the vasculature.

Because various mononuclear cells $(10)$ as well as polymorphonuclear leukocytes $(44,45)$ have been shown to synthesize fibronectin, differences in perfusate concentrations of fibronectin between oxidant and control groups could conceivably arise from differences in cellular composition of perfusate or tissue. However, significant differences in circulating cells were not apparent between these groups. Nor were there discernible differences in tissue cellularity as judged by light microscopy. Endothelial cells, the major cell group in contact with the circulation in our model, secrete intact cellular fibronectin dimers into cell culture medium when grown in tissue culture $(15,16)$. Additionally, these cells have been shown to produce fibronectin in response to tissue injury and inflammation in vivo (28-31). These facts, taken together with our data, suggest that endothelial cells are a potential site of release of fibronectin in response to oxidant stress.

In contrast to the results obtained with oxidants, proteaseinduced vascular injury of the perfused lung was associated with decreased levels of circulating fibronectin measured by immunoassay (ELISA). However, Western blotting revealed that the samples subjected to ELISA did not contain intact fibronectin. Whereas perfusate samples taken prior to addition of protease contained fibronectin with electrophoretic mobility consistent with intact cellular fibronectin, samples at later time points contained fibronectin that had been proteolytically degraded. Since proteolysis was shown to lead to decreased measured values by ELISA, fibronectin may have been proteolytically released from vessels, but not detected by immunoassay due to diminished antigenicity.

The increased fibronectin levels in the lavage fluids from lungs with signs of vascular dysfunction (increased lung weight and lavage protein) could reflect movement of fluid and proteins from the circulation into the alveoli and/or local release of fibronectin from alveolar tissue or cells. Since the predominant protein that was detected in the airspaces of injured lungs comigrated with perfusion fluid BSA in SDS-PAGE, it is likely that fluid and proteins, including fibronectin, moved from the circulation to airspaces during vascular injury in this model.

The association of oxidant exposure with intravascular release of cellular fibronectin in the in vitro perfused rabbit lung raises the possibility that cellular fibronectin could represent a soluble marker in blood or other accessible tissue fluids for oxidant-induced injury. Total plasma fibronectin levels have been noted to increase in rats during experimental systemic inflammatory joint disease (46) and during exposure to hyperoxia (47). Because leukocyte-associated inflammation and hyperoxia both involve generation of oxidants at sites of tissue injury $(1-6,48$, 49 ), the associated accumulation of circulating fibronectin in these models could in part reflect, as in our models, release of fibronectin by oxidant-injured vasculature. Accumulation of such cellular fibronectin in the plasma of intact animals would not be expected to reflect injury to any specific organ, since cells (endothelial cells, fibroblasts, etc.) that produce cellular fibronectin are ubiquitous. However, detection of cellular fibronectin in organ-specific fluid (BAL, synovial fluid, urine) could potentially point to local organ injury. For example, in recent experiments we have caused oxidant-induced injury of lung tissue in intact rabbits by instillation of glucose oxidase and glucose $(\mathrm{GO} / \mathrm{G})$ into the lower airways. This has uniformly (in seven of seven rabbits) led to histologic evidence of injury to the pulmonary parenchyma (including focal disruption of alveolar structure as well as hemorrhage) $4 \mathrm{~h}$ posttreatment. Instillation of catalase with the $\mathrm{GO} / \mathrm{G}$ has uniformly prevented histologic signs of injury (6 out of 6 rabbits), indicating that $\mathrm{H}_{2} \mathrm{O}_{2}$ produced by the GO/G is necessary for injury to occur: Using Western blot analysis, we have detected intact cellular fibronectin in the BAL of all of the rabbits treated with GO/G but none of the rabbits treated with GO/G plus catalase. The ED-containing fibronectin subunits in the BAL of the rabbits with pulmonary tissue injury caused by $\mathrm{GO} / \mathrm{G}$ comigrate during electrophoresis with the slower migrating subunits of the cellular fibronectin in perfusate of isolated rabbit lungs injured by oxidants as described in the present study (Peters and Cochrane, manuscript in preparation). This result also confirms the capacity of oxidants to trigger the appearance of cellular fibronectin in body fluids not limited to in vitro perfused organ systems.

In summary, in this study we have shown that oxidant and protease-induced vascular injury are each associated with characteristic alterations in fibronectin derived from nonhepatic tissue in vitro. Nonhepatic tissue fibronectin (cellular fibronectin) is therefore recognized as an in situ target of these two major classes of inflammatory effector agents. Additionally, we have described a method for the assay of tissue fibronectin to the exclusion of plasma fibronectin. Thus, the use of tissue fibronectin as a probe for effector-specific tissue injury in vivo is now feasible.

\section{Acknowledgments}

We gratefully acknowledge the superb technical assistance of Catherine Case. We thank Dr. Erkki Ruoslahti, Dr. Roger Spragg, Bill Loomis, and Susan and David Revak for their helpful discussions. We also thank Dr. Michael Buchmeier for peptide synthesis, Ward Coppersmith for construction of the lung perfusion chamber, and Monica Bartlett and Lynn LaCivita for typing the manuscript.

Supported by U. S. Public Health Service grants HL 23584 (University of California, San Diego, Specialized Center of Research), and HL 28235, and The Council for Tobacco Research.

\section{References}

1. Cochrane, C. G., R. G. Spragg, and S. D. Revak. 1983. Studies on the pathogenesis of the adult respiratory distress syndrome. Evidence of oxidant activity in bronchoalveolar lavage fluid. J. Clin. Invest. 71: 754-761.

2. Schraufstatter, I. U., S. D. Revak, and C. G. Cochrane. 1984. Proteases and oxidants in experimental pulmonary inflammatory injury. J. Clin. Invest. 73:1175-1184.

3. Revak, S. D., C. L. Rice, I. U. Schraufstatter, W. A. Halsey, B. P. Bohl, R. M. Clancy, and C. G. Cochrane. 1985. Experimental pulmonary inflammatory injury in the monkey. J. Clin. Invest. 76(3):1182-1192.

4. Ward, P. A., G. O. Till, R. Kunkel, and C. Beauchamp. 1983. Evidence for role of hydroxyl radical in complement and neutrophildependent tissue injury. J. Clin. Invest. 72:789-801.

5. Johnson, K. J., and P. A. Ward. 1981. Role of oxygen metabolites in immune complex injury of lung. J. Immunol. 126(6):2365-2369.

6. Till, G. O., K. J. Johnson, R. Kunkel, and P. A. Ward. 1982. Intravascular activation of complement and acute lung injury. Dependency on neutrophils and toxic oxygen metabolites. J. Clin. Invest. 69: 1126-1135.

7. Lee, C. T., A. M. Fein, M. Lippman, H. Holtzman, P. Kimbel, and $G$. Weinbaum. 1981. Elastolytic activity in pulmonary lavage fluid from patients with adult respiratory distress syndrome. $N$. Engl. J. Med. 304:192-196.

8. McGuire, W. W., R. G. Spragg, A. B. Cohen, and C. G. Cochrane. 
1982. Studies on the pathogenesis of the adult respiratory distress syndrome. J. Clin. Invest. 69:543-553.

9. Hynes, R. O. 1982. Fibronectin and its relation to cellular structure and behavior. In Cell Biology of the Extracellular Matrix. E. D. Hay, editor. Plenum Publishing Corp., New York, 295-334.

10. Hynes, R. O., and K. M. Yamada. 1982. Fibronectins. Multifunctional modular proteins. J. Cell Biol. 95:369-377.

11. Ruoslahti, E., E. G. Hayman, M. Pierschbacher, and E. Engvald. 1982. Fibronectin: Purification, immunochemical properties, and biological activities. Methods Enzymol. 82:803-830.

12. Schwarzbauer, J. E., J. I. Paul, and R. O. Hynes. 1985. On the origin of species of fibronectin. Proc. Natl. Acad. Sci. USA. 82:14241428.

13. Kornblihtt, A. R., K. Umezawa, K. Vibe-Pedersen, and F. E. Baralle. 1985. Primary structure of human fibronectin: differential splicing may generate at least 10 polypeptides from a single gene. $E M B O J .4(7)$ : 1755-1759.

14. Tamkun, J. W., and R. O. Hynes. 1985. Plasma fibronectin is synthesized and secreted by hepatocytes. J. Biol. Chem. 258(7):46414647.

15. Jaffe, E. A., and D. F. Mosher. 1978. Synthesis of fibronectin by cultured human endothelial cells. J. Exp. Med. 147:1779-1791.

16. Birdwell, C. R., A. R. Brasier, and L. A. Taylor. 1980. Twodimensional peptide mapping of fibronectins from bovine aortic endothelial cells and bovine plasma. Biochem. Biophys. Res. Commun. 97(2): 574-581.

17. Yamada, K. M., and D. W. Kennedy. 1979. Fibroblast cellular and plasma fibronectins are similar but not identical. J. Cell Biol. 80: 492-498.

18. Yamada, K. M., D. H. Schlesinger, D. W. Kennedy, and I. Pastan. 1977. Characterization of a major fibroblast cell surface glycoprotein. Biochemistry. 16(25):5552-5559.

19. Hayashi, M., and K. M. Yamada. 1981. Differences in domain structure between plasma and cellular fibronectin. J. Biol. Chem. 256(21): 11, 292-300.

20. Atherton, B. T., and R. O. Hynes. 1981. A difference between plasma and cellular fibronectin located with monoclonal antibodies. Cell. 25:133-141.

21. Kornblihtt, A. R., K. Vibe-Pederson, and F. E. Baralle. 1984. Human fibronectin. Molecular cloning evidence for two mRNA species differing by an internal segment coding for a structural domain. $E M B O$. J. 3(1):221-226

22. Kornblihtt, A. R., K. Vibe-Pederson, and F. E. Baralle. 1984. Human fibronectin. Cell specific alternative mRNA splicing generates polypeptide chains differing in the number of internal repeats. Nucleic Acids Res. 12(14):5853-5868.

23. Pettersson, E. E., and R. B. Colvin. 1978. Cold-insoluble globulin (fibronectin, LETS protein) in normal and diseased human glomerulus: papain-sensitive attachment to normal glomeruli and deposition in crescents. Clin. Immunol. Immunopathol. 11:425-436.

24. Grinnell, F., R. E. Billingham, and L. Burgess. 1981. Distribution of fibronectin during wound healing in vivo. J. Invest. Dermatol. 76: 181-189.

25. Repesh, L. A., T. J. Fitzgerald, and L. T. Furcht. 1982. Fibronectin involvement in granulation tissue and wound healing in rabbits. J. Histochem. Cytochem. 30(4):351-358.

26. Torikata, C., B. Villager, C. Kuhn, and J. McDonald. 1985. Ultrastructural distribution of fibronectin in normal and fibrotic human lung. Lab. Invest. 52(4):399-408.

27. Carsons, S., M. W. Mosesson, and H. S. Diamond. 1981. Detection and quantitation of fibronectin in synovial fluid from patients with rheumatic disease. Arth. Rheum. 24(10):1261-1267.

28. Clark, R. A. F., T. H. Quinn, H. J. Winn, J. M. Lanigan, P. Dellepella, and R. B. Colvin. 1982. Fibronectin is produced by blood vessels in response to injury. J. Exp. Med. 156:646-651.

29. Clark, R. A. F., H. F. Dvorak, and R. B. Colvin. 1981. Fibronectin in delayed-type hypersensitivity skin reactions. Associations with vessel permeability and endothelial cell activation. J. Immunol. 126(2):787793.

30. Clark, R. A. F., P. Dellepella, E. Manseau, J. M. Lanigan, H. F. Dvorak, and R. B. Colvin. 1982. Blood vessel fibronectin increases with endothelial cell proliferation and capillary ingrowth during wound healing. J. Invest. Dermatol. 79:269-276.

31. Clark, R. A. F., R. Horsburgh, A. A. Hoffman, H. F. Dvorak, M. W. Mosesson, and R. B. Colvin. 1984. Fibronectin deposition in delayed-type hypersensitivity. Reactions of normals and a patient with afibrinogenemia. J. Clin. Invest. 74:1011-1016.

32. Shasby, D. M., K. M. Vanbenthuysen, R. M. Tate, S. S. Shasby, I. McMurtry, and J. E. Repine. 1982. Granulocytes mediate acute edematous lung injury in rabbits and isolated rabbit lungs perfused with PMA: Role of oxygen radicals. Am. Rev. Respir. Dis. 125:443-447.

33. Hyslop, P. A., and L. A. Sklar. 1984. A quantitative fluorimetric assay for the determination of oxidant production by polymorphonuclear leukocytes: Its use in the simultaneous fluorimetric assay of cellular activation processes. Anal. Biochem. 141:280-286.

34. Laemmli, U. K. 1970. Cleavage of structural proteins during the assembly of the head of bacterioflage $\mathrm{T}_{4}$. Nature (Lond.). 227:680-685.

35. Towbin, H., T. Staehelin, and J. Gordon. 1979. Electrophoretic transfer of proteins from polyacrylamide gels to nitrocellulose sheets. Procedure and some applications. Proc. Natl. Acad. Sci. USA. 76(9): 4350-4354.

36. Engvall, E., and E. Ruoslahti. 1977. Binding of soluble form of fibroblast surface protein, fibronectin, to collagen. Int. J. Cancer. 20:1-5.

37. Bray, B. A., I. Mandl, and G. M. Turino. 1981. Heparin facilitates extraction of tissue fibronectin. Science (Wash., DC). 214:793-795.

38. Merrifield, R. B. 1963. Solid phase peptide synthesis. I. The synthesis of a tetrapeptide. J. Am. Chem. Soc. 85:2149-2154.

39. Dockray, G. J. 1980. Immunological studies on big gastrin using $\mathrm{NH}_{2}$ terminal specific antisera. Regulatory Peptides. 1:169-186.

40. Engvall, E., T. Krasius, U. Weaver, and E. Ruoslahti. 1983. Laminin from rat yolk sac tumor: Isolation, partial characterization, and comparison with mouse laminin. Arch. Biochem. Biophys. 222(2):649658.

41. Engvall, E. 1980. Enzyme immunoassay ELISA and EMIT. Methods Enzymol. 70:419-439.

42. Lowry, O. H., N. J. Rosebrough, A. L. Farr, and R. J. Randall. 1951. Protein measurement with the Folin phenol reagent. J. Biol. Chem. 193:265-275.

43. Quaroni, A., K. J. Isselbacher, and E. Ruoslahti. 1978. Fibronectin synthesis by epithelial crypt cells of rat small intestine. Proc. Natl. Acad. Sci. USA. 75(11):5548-5552.

44. Weissmann, G., E. Pearstein, H. D. Perez, S. Falkow, I. M. Goldstein, and S. T. Hoffstein. 1980. Neutrophils synthesize and deposit fibronectin on surfaces to which they attach. Assoc. Am. Physicians. 93: 72-84.

45. Menard, C., A. D. Beaulieu, M. Audette, J. Corbeil, and L. Latulippe. 1985. Studies on fibronectin in inflammatory vs. non-inflammatory polymorphonuclear leukocytes of patients with rheumatoid arthritis. II. Synthesis and release of fibronectin in vitro. Clin. Exp. Immunol. 60:347-354.

46. Stecher, V., J. Kaplan, K. Connolly, Z. Mielens, and J. Saelens. 1986. Fibronectin in acute and chronic inflammation. Arth. Rheum. 29(3):394-399.

47. Glass, M., J. E. Kaplan, E. Macarak, S. Ankberg, and A. Fisher. 1984. Serum fibronectin is elevated during normobaric and hyperbaric oxygen exposure in rats. Am. Rev. Respir. Dis. 130:237-241.

48. Freeman, B. A., and J. D. Crapo. 1981. Hyperoxia increases oxygen radical production in rat lungs and lung mitochondria. J. Biol. Chem. 256(21):10986-10992.

49. Turrens, J. F., J. D. Crapo, and B. A. Freeman. 1984. Protection against oxygen toxicity by intravenous injection of liposome-entrapped catalase and superoxide dismutase. J. Clin. Invest. 73:87-95. 